\title{
Ação da cardioplegia na proteção miocárdica: estudo experimental através das réplicas de criofraturas
}

\author{
Luis Alberto DALLAN*, Sérgio Almeida de OLIVEIRA*, Lurdes HIGUCHI*, Edgard A. LOPES*, Antônio \\ SESSO*, Geraldo VERGINELLI*, Adib D. JATENE*
}

RBCCV $44205-4$

\begin{abstract}
DALLAN, L. A.; OLIVEIRA, S. A.; HIGUCHI, L.; LOPES, E. A ; SESSO, A.; VERGINELLI, G.: JATENE. A. D. - Ação da cardioplegia na proteção miocárdica: estudo experimental através das réplicas de criofraturas. Rev. Bras. Cir. Cardiovasc., 2(3): 200-211, 1987.

RESUMO: Foi avaliado, experimentalmente, o grau de proteção miocárdica oferecido por soluçōes cardioplégicas e hipotermia, à anóxia induzida pela interrupção do fluxo sangüineo coronário em 20 cães. $A$ isquemia miocárdica foi obtida através do pinçamento da aorta ascendente por 60 minutos, após a instalaçāo de circulação extracorpórea, seguida de reperfusão miocárdica por 360 minutos. Os animais foram divididos em 4 grupos de cães. No primeiro (Grupo I), denominado controle, foi induzida anóxia miocárdica em normotermia e sem administração de solução cardioplégica. No segundo (Grupo II), os animais foram esfriados a $28^{\circ} \mathrm{C}$, antes do início da anóxia miocárdica. Neste grupo, também não foi utilizada a solução cardioplégica. No terceiro e quarto grupos, respectivamente Grupo III e Grupo IV, além da hipotermia sistêmica de $28^{\circ} \mathrm{C}$. foi realizada perfusão coronária de solução cardioplégica a $40^{\circ} \mathrm{C}$. A solução cardioplégica continha $\mathrm{NaCl}$. $\mathrm{KCl}, \mathrm{CaCl}_{2}$, lidocaína, verapamil, $\mathrm{NaHCO}_{3}, \mathrm{MgSO}_{4}$, sendo o veículo de infusão soro glicosado no Grupo III e sangue autógeno no Grupo IV. Foram estudadas as alteraçōes ultra-estruturais (réplicas de criofraturas) em biópsias de ventrículo esquerdo, dando-se especial ênfase às alteraçōes do sarcolema e membramas mitocondriais, principalmente através da visibilização de aglutinação e rarefação das partículas de proteina presentes nessas estruturas. Conclui-se que os 2 tipos de solução cardioplégica utilizados, juntamente com hipotermia sistêmica, proporcionaram proteção eficaz ao miocárdio isquêmico, sem que pudéssemos, entretanto, demonstrar a superioridade de uma delas. A hipotermia sistêmica isolada (Grupo II) não propiciou boa proteção à célula miocárdica em anóxia. Os animais do Grupo I (controle) apresentaram grande compromentimento na estrutura e função do miocárdio.
\end{abstract}

DESCRITORES: proteção miocárdica, cardioplegia; proteção miocárdica, experimental.

\section{INTRODUÇĀO}

A parada cardiaca anóxica é recurso técnico largamente utilizado durante a correçāo cirúrgica das cardiopatias. Sua indução pelo pinçamento da aorta ascendente, com interrupção do fluxo sangüíneo, é manobra técnica simples, que facilita, consideravelmente, 0 ato operatório. Entretanto, a isquemia induzida lesa o miocárdio, sendo este comprometimento tanto mais acen- tuado quanto mais prolongada a anóxia. As alteraçōes inicialmente reversíveis com a reperfusāo miocárdica podem tornar-se definitivas, após períodos mais longos de anóxia. Ainda nāo é possivel determinar-se, com precisão, o limite de tempo a partir do qual essas lesões miocárdicas tornam-se irreversiveis.

A necessidade de períodos mais prolongados de parada cardiaca, para realizaçāo de operaçōes mais lon-

Trabalho realizado no Instituto do Coração do Hospital das Clínicas da Faculdade de Medicina da Universidade de São Paulo. São Paulo, SP Brasil.

Apresentado ao 14: Congresso Nacional de Cirurgia Cardiaca. Salvador, BA, 27 e 28 de março, 1987.

- Do Instituto do Coração do Hospital das Clinicas da Faculdade de Medicina da Universidade de São Paulo

Endereço para separatas: Luis Alberto Dallan. Rua Pelotas. 323. Apto. 152. 04012 São Paulo. SP. Brasil 
DALLAN, L. A.; OLIVEIRA, S. A.; HIGUCHI, L.; LOPES, E. A.; SESSO, A.; VERGINELLI, G.; JATENE, A. D. - Ação da cardioplegia na proteção miocárdica: estudo experimental através das réplicas de criofraturas. Rev. Bras. Cir. Cardiovasc., 2(3): 200-211, 1987.

gas, ou mais complexas, levou ao desenvolvimento de medidas protetoras do miocárdio.

Estudos desenvolvidos, no início da década de 1950, reconheceram a inibição metabólica proporcionada pela hipotermia ${ }^{4}{ }^{19}$. Já em 1953, esses conhecimentos foram aplicados no resfriamento do organismo humano, tendo sido realizada a primeira operação cardiaca a céu aberto, com hipotermia sistêmica de $30^{\circ} \mathrm{C}$ e parada circulatória, logrando fechar com sucesso uma comunicação interatrial ${ }^{33}$.

No final da década de 50 e, especialmente, nos primeiros anos da década seguinte, foram realizadas numerosas tentativas de proteção miocárdica, através de perfusão sangüínea coronária normo ou hipotérmica, associada, ou não, ao esfriamento tópico do coraçāo ${ }^{15}$. $27,28,34,47$.

Em 1956, porém, COOLEY et alii ${ }^{12}$ mostraram meIhores resultados cirúrgicos com a utilização da simples parada cardíaca anóxica, quando comparada aos resultados obtidos pelos métodos até então estabelecidos de proteção miocárdica, desestimulando sua utilização. Embora paradoxal, a explicação baseava-se no fato de que o coração parado consumia menos energia do que batendo de maneira inadequada, ou fibrilando. Indiretamente, o coração sem batimentos e relaxado proporcionava campo operatório favorável a correçōes cirúrgicas mais rápidas. Estas evidências e, especialmente, o insucesso de MELROSE et alii ${ }^{38}$, em 1955, na indução de parada cardíaca injetando, na raiz da aorta, citrato de potássio em altas concentrações e com elevada osmolaridade, condenaram o método, que ficou no esquecimento por mais de uma década.

A sistematização cirúrgica, o aprimoramento dos aparelhos de circulação extracorpórea e, especialmente, $a$ indicaçăo da abordagem cirúrgica em ventrículos com função já bastante comprometida, despertaram o interesse por novos métodos de proteção miocárdica. Os insucessos antes atribuídos a deficiências no sistema de circulação extracorpórea, especialmente discrasias sangüíneas e microembolias, não mais se justificavam. Por outro lado, as unidades de recuperação pós-operatória aparelharam-se, convenientemente, para a adequada avaliação hemodinâmica do paciente, deixando transparecer os evidentes danos celulares relacionados com a parada anóxica. Simultaneamente, a melhor compreensão da fisiologia da contratilidade da célula miocárdica e, em especial, o reconhecimento das alteraçōes estruturais decorrentes da anóxia ${ }^{1}, 3,13,25,35,37,41$, não permitiram uma atitude passiva diante de quadros catastróficos observados, com freqüência, no intra e no pós-operatório.

A partir de $1972, \mathrm{KIRCH}$ et alii ${ }^{32}$ retornaram aos trabalhos de MELROSE et alii ${ }^{38}$, com novo enfoque, visando obter proteção miocárdica através de substâncias que pudessem induzir à cardioplegia. Desde então, sucessivos artigos surgiram, na literatura, mostrando a experiência de diversos Serviços de cirurgia cardíaca com o seu emprego $0^{5}$. 8, 16, 18, 20, 21, 22, 39, 40, 42, 44, 45. 50. Apesar do grande número de publicaçōes, ainda persistem controvérsias relativas à proteção ideal da estrutura celular e das organelas à anóxia, seja quanto à composição da solução cardioplégica, ou mesmo quanto à validade de seu emprego, o que nos motivou a desenvolver o presente estudo.

A partir da quantificação das lesões ultra-estruturais observadas na célula miocárdica, decorrentes da anóxia, e suas implicaçőes hemodinâmicas e metabólicas, procuramos, através de estudo experimental em cães, avaliar a real proteção miocárdica promovida pela hipotermia isolada, ou associada a diferentes formas de cardioplegia, visando estabelecer procedimentos que venham minimizar os efeitos deletérios provocados pela parada cardíaca anóxica.

\section{MATERIAL E MÉTODOS}

Foram estudados, na Divisão de Experimentação do Instituto do Coração, do Hospital das Clínicas da Faculdade de Medicina da Universidade de São Paulo, 20 cães mestiços, de ambos os sexos, com pesos variáveis de 12,0 a $20,5 \mathrm{Kg}$, subdivididos em 4 grupos:

Grupo l) 5 cães submetidos a anóxia cardíaca por 60 minutos, em condições normotérmicas;

Grupo II) 5 cāes submetidos a anóxia cardíaca por 60 minutos, em condiçōes hipotérmicas $\left(28^{\circ} \mathrm{C}\right)$;

Grupo III) 5 cães submetidos a anóxia cardíaca por 60 minutos, em condiçōes hipotérmicas $\left(28^{\circ} \mathrm{C}\right)$, tendo recebido duas infusōes de solução cardioplégica (soro glicosado como substrato básico);

Grupo IV) 5 cães submetidos a anóxia cardiaca por 60 minutos, em condiçōes hipotérmicas $\left(28^{\circ} \mathrm{C}\right)$, tendo recebido duas infusōes de solução cardioplégica (sangue como substrato básico).

\section{Técnica cirúrgica}

Todos os animais foram submetidos a anestesia geral: tiopental sódico (33 mg/Kg/peso), entubação orotraqueal e mantidos com respiração controlada.

O coração e os vasos da base foram expostos através de toracotomia mediana transesternal. Após heparinização (3 mg/Kg/peso), estabeleceu-se circulação extracorpórea através da drenagem venosa de ambas as veias cava. Paralelamente, dissecou-se a artéria femoral esquerda $e$, através de sua canulação, foi processada a reinfusăo do sangue já oxigenado. Uma vez instalada a circulação extracorpórea, o átrio esquerdo foi drenado através de incisão em aurícula esquerda, evitando-se a distenção cardíaca. Empregou-se bomba arterial de roletes e oxigenador de bolhas de coluna variável. A 
DALLAN, L. A.; OLIVEIRA, S. A.: HIGUCHI, L.: LOPES, E. A.; SESSO. A.: VERGINELLI, G.; JATENE, A. D. - Ação da cardioplegia na proteção miocárdica: estudo experimental através das réplicas de criofraturas. Rev. Bras. Cir. CardiovasC. 2(3): 200-211. 1987.

perfusão foi iniciada com hemodiluição total, através de solução de Ringer simples $(400 \mathrm{ml})$, dextran 40 (250 $\mathrm{ml})$ e manitol $20 \%(50 \mathrm{ml})$, mantendo-se fluxo variável de 40 a $100 \mathrm{ml} / \mathrm{Kg} /$ minuto.

\section{Soluçâo Cardioplégica}

As soluçōes cardioplégicas empregadas foram baseadas na proposta por GOMES et alii ${ }^{20}$, a saber:

\section{Solução I)}

Soro glicosado $5 \% 1.000 \mathrm{ml}$

$\mathrm{NaCl} 30 \% \quad 60 \mathrm{mEq} / \mathrm{l}$

$\mathrm{KCl} 19,1 \% \quad 25 \mathrm{mEq} / \mathrm{l}$

$\mathrm{MgSO}_{4} 10 \% \quad 32 \mathrm{mEq} / \mathrm{l}$

$\mathrm{CaCl}_{2} 10 \% \quad 2,5 \mathrm{mEq} / \mathrm{l}$

Lidocaina $\quad 40 \mathrm{mg} / \mathrm{I}$

Verapamil $\quad 0,2 \mathrm{mg} / \mathrm{I}$

$\mathrm{NaHCO}_{3} 10 \% \quad 2,4 \mathrm{mEq} / \mathrm{l}$ (q.s.p. pH entre 7,45 e 7,77 )

Osmolaridade $\quad 400-410 \mathrm{mOsm}$

Solução II) Composiçāo semelhante à solução I, sem o componente $\mathrm{MgSO}_{4}$.

Solução III) Composta pelos mesmos elementos da solução I, com exceção do veículo de perfusão, constituido por sangue (do próprio cão, ou de outro cão com reação cruzada compativel), ao invés de soro glicosado.

Solução IV) Semelhante à solução III, porém sem o componente $\mathrm{MgSO}_{4}$.

A solução cardioplégica foi administrada por punçāo da raiz da aorta após seu pinçamento, tendo sido utilizado volume de $15 \mathrm{ml} / \mathrm{Kg} /$ peso e pressão de infusão em torno de $50 \mathrm{mmHg}$ na raiz da aorta.

As perfusōes foram realizadas em duas etapas: a primeira, imediatamente após o pinçamento da aorta e a segunda, decorridos 30 minutos da primeira.

Essas soluçōes foram resfriadas entre 4 e $10^{\circ} \mathrm{C}$ e a temperatura miocárdica, determinada por sensor térmico posicionado no septo interventricular. A temperatura miocárdica média dos cães dos grupos III e IV variou de 9 a $14^{\circ} \mathrm{C}$, com média de $11,5^{\circ} \mathrm{C}$, enquanto que, nos grupos I e II, a temperatura miocárdica média foi, respectivamente, $36,2^{\circ} \mathrm{C}$ e $29,1^{\circ} \mathrm{C}$.

\section{Réplicas de Criofratura}

As amostras de músculo cardíaco foram retiradas da parede anterior do ventrículo esquerdo (VE), através de incisāo transmural profunda e preparadas para réplicas de criofratura. Foram recortadas em fragmentos de $1 \mathrm{~mm}$, em seu maior eixo, e imersas em glutaraldeído a $2 \%, 0,1 \mathrm{M}$ e tampão de fosfato $(\mathrm{pH}=7,3)$, por uma hora. Passadas, a seguir, para a solução de glicerol a $10 \%$ e tampão fosfato $0,1 \mathrm{M}(\mathrm{pH}=7,3)$ e, posteriormente, para uma solução de glicerol a $25 \%$ em tampão fosfato $0,1 \mathrm{M}(\mathrm{pH}=7,3)$.
O congelamento se processou à velocidade superior a $-100^{\circ} \mathrm{C} /$ segundo, através da imersão dos fragmentos em Freon $22 \mathrm{a}-155^{\circ} \mathrm{C}$ por 10 segundos. As amostras, acondicionadas em suporte de ouro-irídio, foram transferidas para nitrogênio liqüido $\mathrm{a}-196^{\circ} \mathrm{C}$, e levadas para câmara de equipamento Balzers-Baf 301 para freezeetching, à temperatura de $-150^{\circ} \mathrm{C}$.

Ao obter-se vácuo de $10^{-1}$ Torr, elevou-se a temperatura para $-110^{\circ} \mathrm{C}$, tendo, então, sido realizadas as fraturas. Seguiu-se depósito sobre as superficies expostas das fraturas de mistura platina-carbono (em partes de $95 \%$ e $5 \%$, respectivamente), a um ângulo de $45^{\circ}$. Estas misturas foram recobertas com filme suporte de carbono com $20 \mathrm{~mm}$ de espessura. Os fragmentos de tecido sob réplicas foram, entāo, dissolvidos através de tratamento com soluçāo de ácido sulfúrico, ou hipoclorito de sódio, por 12 a 18 horas. As réplicas foram colhidas em telas com película de parlódio e examinadas ao microscópio Philips 301.

\section{Procedimentos nos Grupos}

Grupo I) Cinco cães submetidos a circulação extracorpórea (CEC) e anóxia miocárdica normotérmica, através do pinçamento da aorta ascendente (acima dos óstios coronários), por período de 60 minutos. Decorrido este prazo, a aorta foi despinçada, com conseqüente reperfusão do miocárdio. Os batimentos cardiacos restabeleceram-se espontaneamente, ou através de desfibrilação miocárdica direta. Normalizadas as condiçōes hemodinâmicas, os pulmões foram ventilados, a aurícula esquerda, saturada e a circulação extracorpórea foi interrompida. Foram retiradas biópsias de ventrículo esquerdo para réplicas de criofratura, nos tempos: pré CEC; 60 minutos pós-isquemia miocárdica; 360 minutos pós reperfusão miocárdica.

Grupo II) Cinco cães submetidos a anóxia miocárdica hipotérmica $\left(28^{\circ} \mathrm{C}\right)$. Após instalada a circulaçâo extracorpórea, os animais foram esfriados, progressivamente, até $28^{\circ} \mathrm{C}$, através do permutador de calor do oxigenador, ocasião em que a aorta era pinçada por 60 minutos. O reaquecimento foi iniciado já aos 30 minutos de anóxia miocárdica, permitindo obter-se temperatura esofágica superior a $35^{\circ} \mathrm{C}$, ao final dos 60 minutos, quando se retirava a pinça da aorta. Os batimentos cardiacos foram obtidos espontaneamente, ou através de desfibrilação com pás internas. De maneira análoga ao Grupo I, aguardava-se bom restabelecimento da contratilidade cardiaca, para a interrupção da CEC, mantendo-se os cães anestesiados e em ventilação pulmonar assistida. À semelhança do Grupo I, foram retiradas biópsias de VE, para réplicas de criofratura antes da CEC, $6 \mathrm{C}$ m:in:L'os pós isquemia miocárdica e 360 minutos pós reperfusão miocárdica.

Grupo III) Cinco cães foram esfriados à temperatura de $28^{\circ} \mathrm{C}$ e submetidos a anóxia miocárdica por 60 minutos, aos quais se associou infusāo de solução cardioplé- 
DALLAN, L. A.; OLIVEIRA, S. A.; HIGUCHI, L.: LOPES, E. A.: SESSO. A.: VERGINELLI, G.; JATENE. A. D. - Ação da cardioplegia na proteção miocárdica: estudio experimental atraves das réplicas de criofraturas. Rev. Bras. Cir. Cardiovasc., 2(3): 200-211, 1987

gica. A primeira infusão de solução cardioplágica iniciava-se imediatamente após o pinçamento da aorta, utilizando-se a solução cardioplégica I. Decorridos 30 minutos, o procedimento era repetido, com a solução cardioplégica II, até totalizar-se o volume preconizado. Foram colhidas amostras de VE para réplicas de criofraturas, nos mesmos tempos que os grupos anteriores.

Grupo IV) Cinco cães submetidos aos mesmos procedimentos aplicados aos do Grupo III, modificando-se apenas as soluçōes cardioplégicas, que, neste grupo, foram as de número III e IV, contendo sangue como veículo de infusão.

\section{RESULTADOS}

Em todos os animais, não foram observadas alteraçōes morfológicas dignas de registro, em nenhuma das amostras de VE obtidas antes da instalaçāo de CEC.

As figuras de número 1 a 3 exemplificam alguns dos aspectos mais relevantes das fibras cardiacas (amostra 1), quando analisadas através das réplicas de suas criofraturas.

\section{Sarcolema}

A análise de extensas áreas fraturadas do sarcolema nos permitiu observar seu aspecto ondulado, representado, alternadamente, por hemifaces $\mathrm{P}$ e $\mathrm{E}$. A hemiface $\mathrm{P}$ (Sp na Figura 1) corresponde à membrana nuclear voltada para o interior da célula, contendo invaginaçōes a intervalos regulares, as porçōes superficiais do sistema $\mathrm{T}$ ( $\mathrm{T}$ na Figura 1 ) e inúmeras pequenas reentrâncias, atribuídas às vesiculas de endocitose. $\mathrm{Na}$ hemiface $E$ (Se na Figura 1), observamos o aspecto externo da membrana celular. Nele, os túbulos $T$ e as vesículas de endocitose apresentam-se, respectivamente, com projeções tubulares e elevaçōes globulares menores. A hemiface P caracteriza-se por apresentar numerosas partículas intramembranosas (PIMs) distribuidas homogeneamente. Esse número é substancialmente menor na face $\mathrm{E}$.

\section{Sistema Retículo-Sarcoplasmático e Túbulos}

O sistema retículo-sarcoplasmático é formado por canais achatados intercomunicantes, contendo numerosas PIMs na hemiface $P$ e raras na hemiface $E$. Os túbulos $\mathrm{T}$, invariavelmente, continuam-se com sarcolema, atravessando, perpendicularmente, o interior da fibra cardiaca, em geral margeados por mitocôndrias. No miocárdio normal do cão, observamos, com freqüência, numerosas PIMs na hemiface $\mathrm{P}$ dos túbulos $\mathrm{T}$, o que nāo se repete na hemiface $\mathrm{E}$.

\section{Mitocôndrias}

As mitocôndrias localizam-se abaixo do sarcolema e em meio aos miofilamentos. Seu aspecto, nas réplicas de criofratura, é cilindrico, composto por hemiface $P$, com membrana mitocondrial interna e externa (Mlp e MEp na Figura 2) e hemiface E, igualmente com membranas interna e externa (MEe na Figura 2).

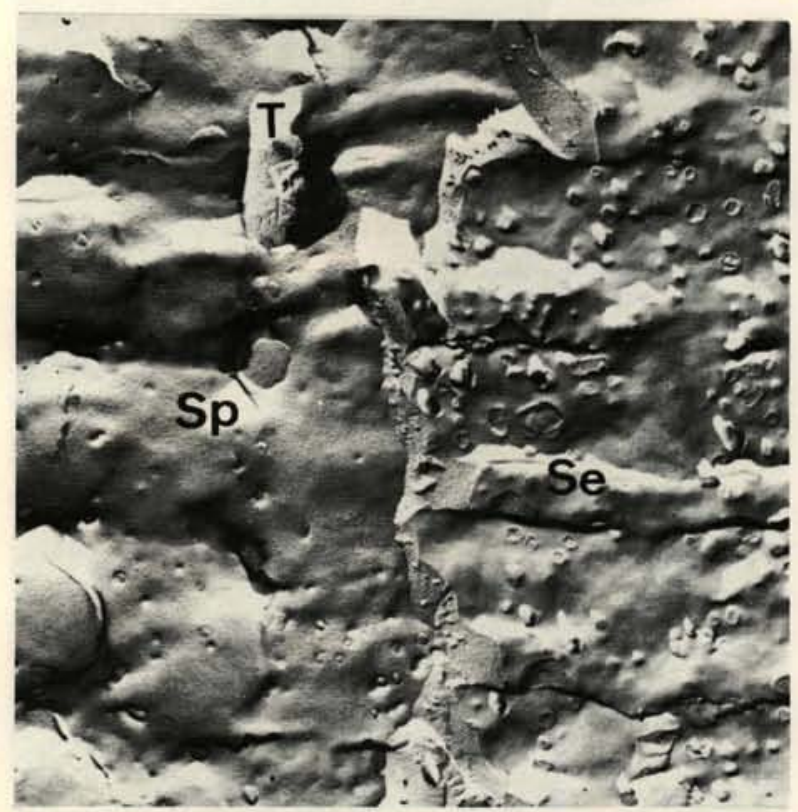

Fig. 1-Amostra I (controle). Réplicas de criofratura das faces P (Sp) e E (Se) do sarcolema. $(14.000 \mathrm{x})$

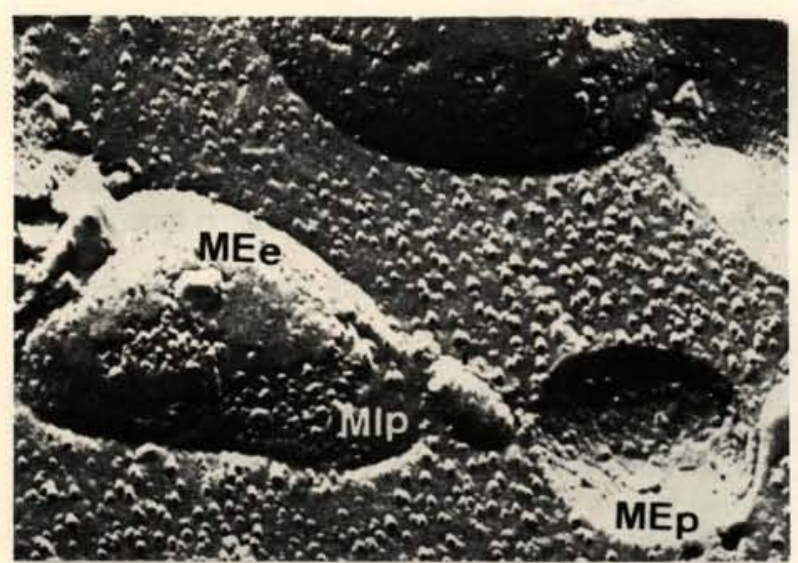

Fig. 2 - Amostra I (controle). Diversas faces de fraturas das membranas mitocondriais: hemiface $\mathrm{P}$ com membrana mitocondrial interna e externa (Mlp e MEp) e hemiface E com membrana mitocondrial externa (MEe). $(70.000 \mathrm{x})$.

\section{Miofilamentos e Núcleo}

Os miofilamentos finos e grossos somente são visibilizados quando da secção transversa da fibra cardíaca, ao nível de seu maior eixo, ocasião em que emergem sobre a superfície da fratura. O núcleo celular caracteriza-se pela presença de numerosos poros ( $p o$ na Figura 
DALLAN, L. A.; OLIVEIRA, S. A.: HIGUCHI, L.; LOPES, E. A.; SESSO, A.; VERGINELLI, G.; JATENE, A. D. - Ação da cardioplegia na proteçâo miocárdica: estudo experimental através das réplicas de criofraturas. Rev. Bras. Cir. Cardiovasc., 2(3): 200-211. 1987

3) em sua membrana dupla, com inúmeras PIMs na hemiface P da membrana nuclear interna (NIp ha Figura 3).

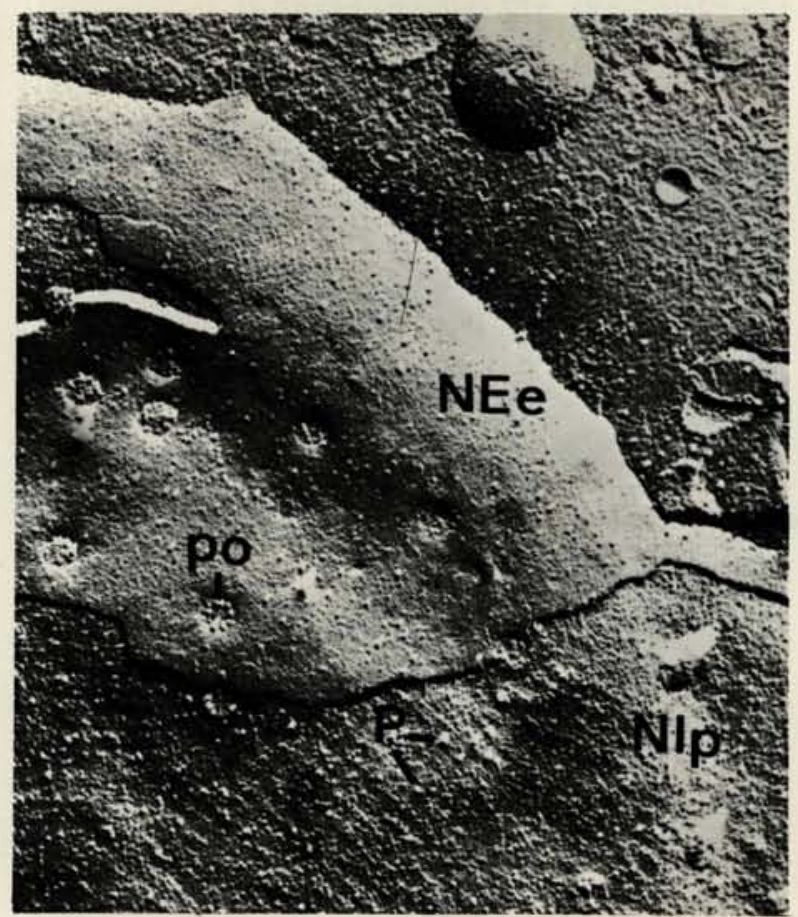

Fig. 3-Núcleo celular, com numerosas partículas intramembranosas (P) em sua membrana interna de hemiface $\mathrm{P}(\mathrm{NIp})$, e presença de poros (po) em sua membrana externa da hemiface $E$ (NEe). $(50.400 x)$.

\section{Capilares}

As vesículas de endocitose dos capilares assumem aspectos peculiares com a fratura, caracterizados por depressões na face $\mathrm{P}$ e protuberâncias na face $\mathrm{E}$.

Ao final de 60 minutos de anóxia, observamos (amostra 2):

Grupo I) Em todos os cães deste grupo, a característica mais comum foi a diminuição das PIMs na face $P$ do carcolema (Sp na Figura 4). Essas alteraçōes não se apresentavam homogêneas, em todos os campos estudados, variando desde discreto decréscimo, até reduções acentuadas em seu número, com tendência à agregação ( $\longrightarrow$ na Figura 4). Em 3 dos 5 cães deste grupo, notamos nítida descontinuidade da fase lipidica do sarcolema P ( na Figura 4). O retículo sarcoplasmático encontrava-se invariavelmente dilatado, assim como os túbulos $\mathrm{T}$, em cuja face $\mathrm{P}$ notava-se diminuição do número de PIMs (ver P em Tp na Figura 5). As mitocôndrias adquiriram conformação alongada e tumefeita, com aparente diminuição no número de PIMs na face $\mathrm{E}$ da membrana mitocondrial externa (MEe na Figura 6) e face $P$ da membrana mitocondrial interna (Mlp na Figura 6). Ausências focais de miofilamentos foram raramente observadas (0 na Figura 6) e a membrana dupla nuclear encontrava-se conservada. Os capilares apresentaram grande variaçăo em sua morfologia. Observamos células endoteliais com diminuição acentuada de PIMs em suas hemiface $P$ e E, alternadas com outras semelhantes ao grupo controle.

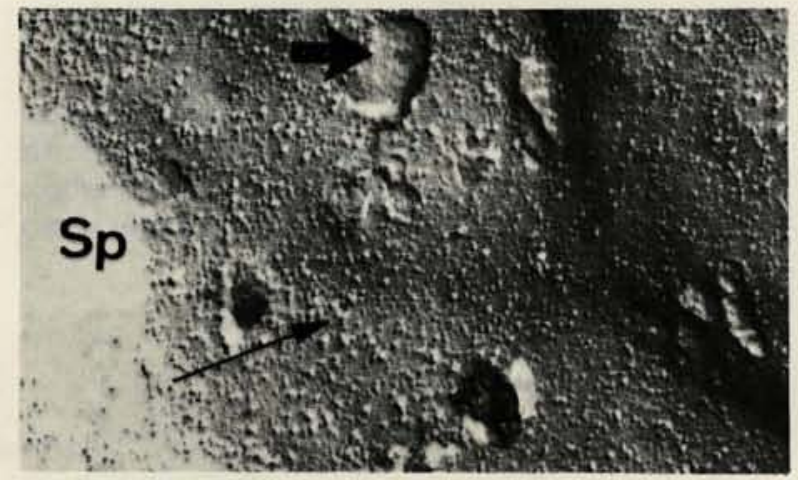

Fig. 4-60 minutos de isquemia. Grupo I. Hemiface P do sarcolema, com descontinuidade de sua fase lipidica ( e agregação das particulas intramembranosas $\longrightarrow$. $(70.000 \mathrm{x})$.

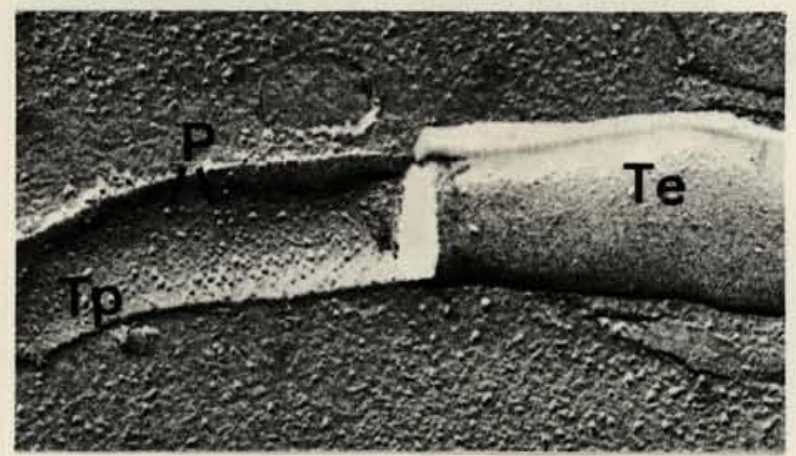

Fig. 5- 60 minutos de isquemia. Grupo I. Túbulo T com diminuiçâo no número de particulas intramembranosas $(P)$ em suas hemifaces $P(T p)$ e $E(T e)$. $(56.000 x)$.

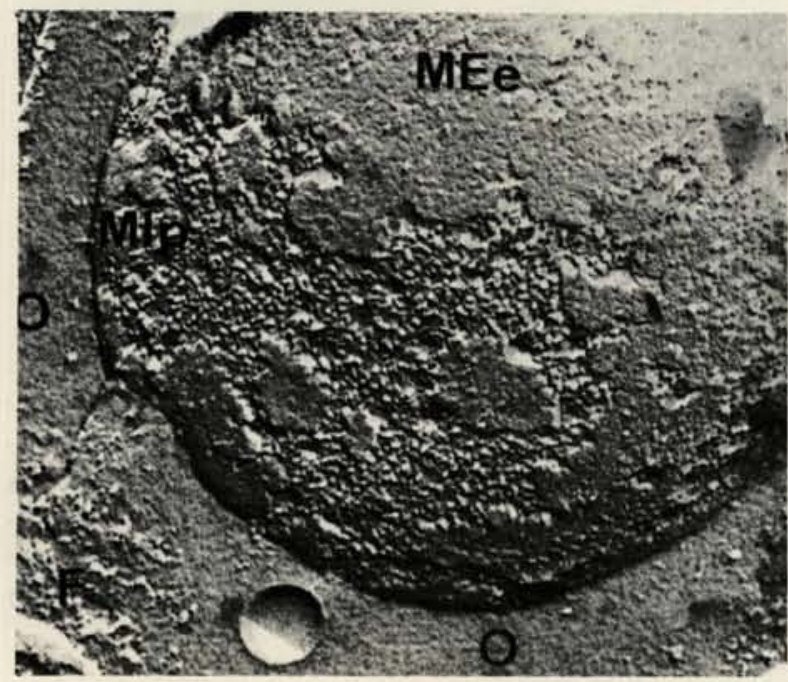

Fig. 6-60 minutos de isquemia. Grupo I. Mitocôndria com diminuiçăo no número de particulas intramembranosas da hemiface $\mathrm{P}$ de sua membrana interna (Mlp) e da hemiface $\mathrm{E}$ de sua membrana externa (MEe). (70.000 x) 
DALLAN, L. A.; OLIVEIRA, S. A.; HIGUCHI, L.; LOPES, E. A.; SESSO, A.; VERGINELLI, G.; JATENE, A. D. - Ação da cardioplegia na proteção miocárdica: estudo experimental através das réplicas de criofraturas. Rev. Bras. Cir. Cardiovasc., 2(3): 200-211. 1987

Grupo II) A diminuição e agregação das PIMs da face $P$ do sarcolema, embora discreta, constituiu-se em achado freqüente ( $\longrightarrow$ e P na Figura 7). Observamos, também, alguns sarcolemas cuja hemiface $P$ apresentava nitida descontinuidade de sua fase lipidica ( na Figura 7). As mitocôndrias apresentavam-se globosas e com tumefação variável. Pudemos, num dos cães, visibilizar áreas de fissura na face $E$ de sua membrana externa (ver $\longrightarrow$ em MEe na Figura 8). A configuração geral das demais estruturas nāo diferiu, significativamente, do observado nas biópsias de controle.

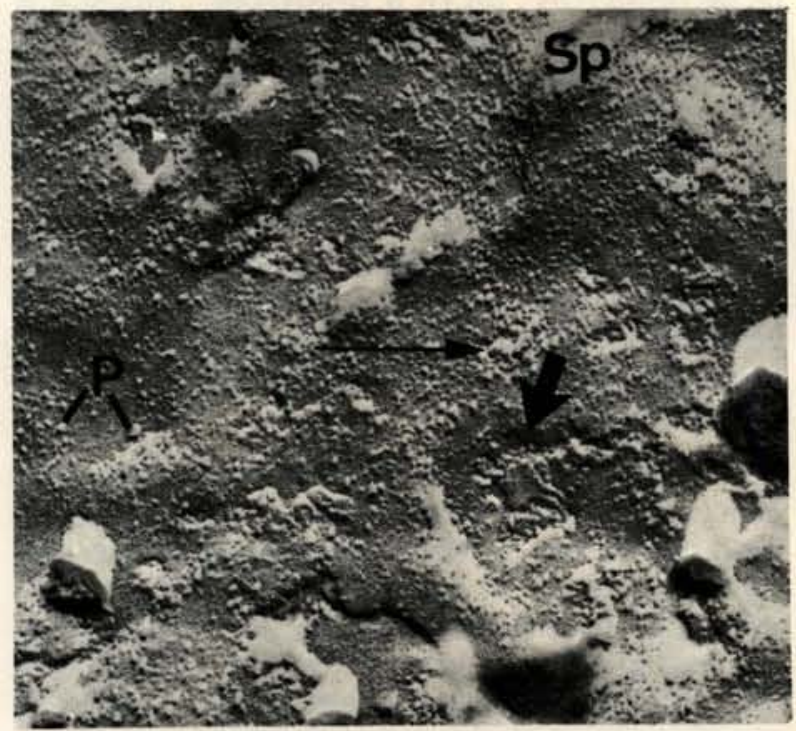

Fig. 7 - 60 minutos de isquemia. Grupo II. Hemiface P do sarcolema, com descontinuidade de sua fase lipidica ( $\Rightarrow$ ) e discreta diminuição e agregaçāo das partículas intramembranosas $(\longrightarrow)$. $(70.000 x)$

Grupos III e IV) Não observamos alteraçōes subcelulares que divergissem, substancialmente, do grupo controle. As PIMs das hamifaces P e E do sarcolema, aparentemente, apresentavam número e distribuição normais, assim como as demais estruturas.

Decorridos 360 minutos de reperfusão miocárdica, constatamos (amostra 3):

Grupo I) Em 3 cães deste grupo, notamos ainda maior diminuição e agregação nas PIMs, quando comparadas à amostra 2, com áreas de descontinuidade da fase lipídica do sarcolema E. Nos demais, entretanto, o número de PIMs da hemiface $\mathrm{P}$ do sarcolema assemelhava-se aos das amostras-controle, assim como a configuraçāo geral do sarcolema.

Observamos menor número de mitocôndrias com acentuado comprometimento, caracterizado por tumefação, presença de áreas lisas na membrana interna, dilataçōes saculares de suas cristas ( $*$ na Figura 9 ), e mesmo pela ocorrência de pequenas fendas na face $\mathrm{E}$ da membrana mitocondrial externa $(\longrightarrow$ em MEe na figura 9). Em contrapartida, notamos, numa mesma amostra, outras mitocôndrias com pouca alteração em sua estrutura e número de partículas. Os capilares, de maneira geral, apresentaram sinais de recuperaçâo, quando comparados à fase de anóxia. Embora ainda notássemos uma diminuiçăo esporádica de PIMs de suas células endoteliais, o aspecto das vesículas de endocitose assemelhava-se ao normal ( $\mathrm{PeV}$ em $\mathrm{Cp}$ na $\mathrm{Fi}$ gura 10).

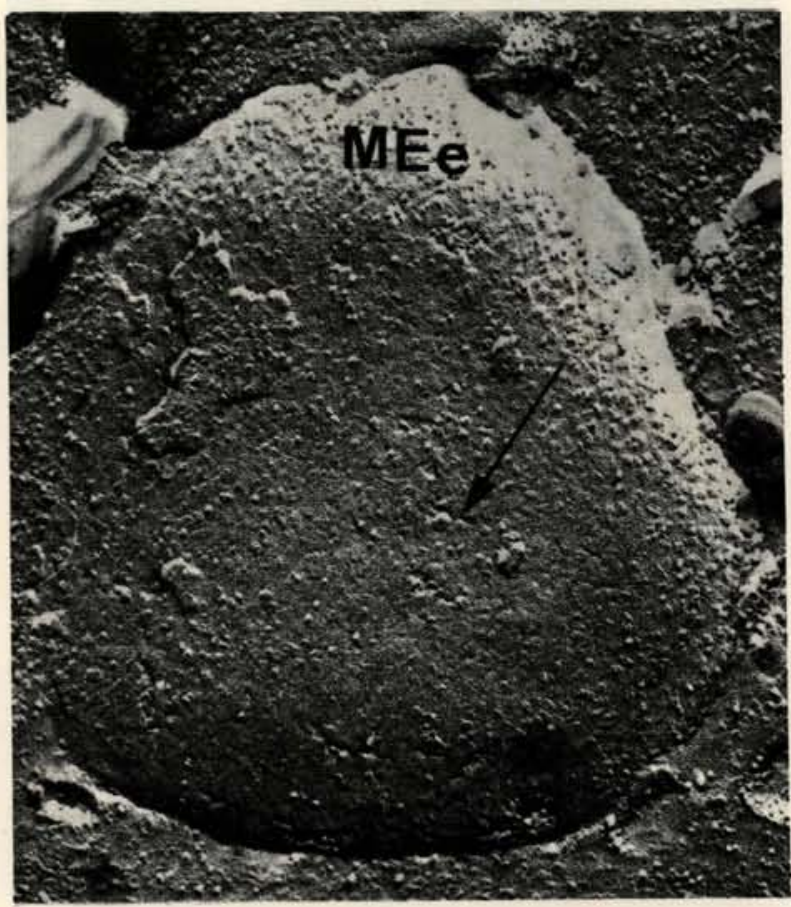

Fig. 8-60 minutos de isquemia. Grupo II. Hemiface $P$ da membrana externa mitocondrial, com tumefação e áreas de fissura $(\longrightarrow) .(70.000 \mathrm{x})$.

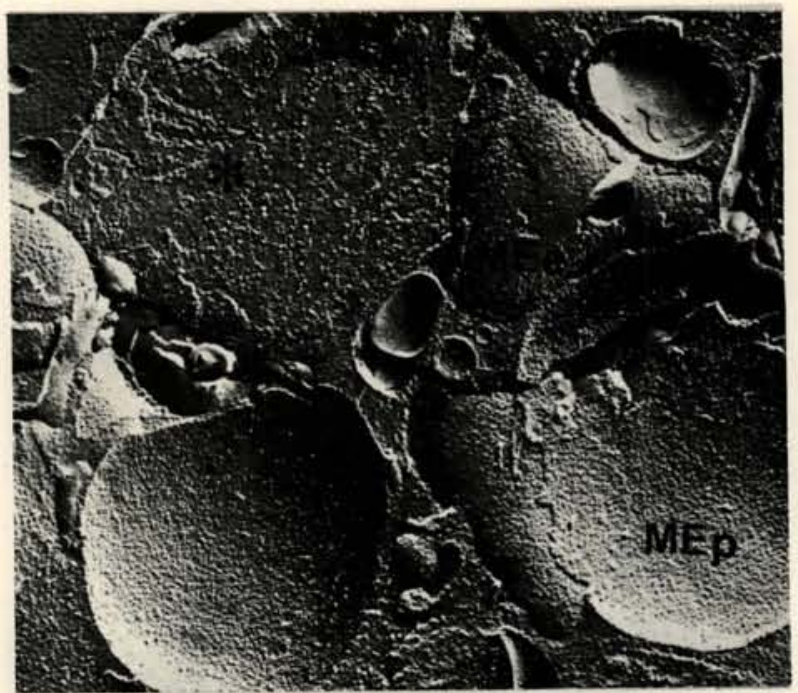

Fig. 9 - 360 minutos de reperfusão miocárdica. Grupo 1. Mitocôndrias com dilataçōes saculares em suas cristas (*) e com fendas $(\longrightarrow$ em suas membranas externas (MEp e MEe). (38.500 $\mathrm{x})$. 
DALLAN, L. A.; OLIVEIRA, S. A.; HIGUCHI, L.; LOPES, E. A.; SESSO, A.; VERGINELLI, G.; JATENE, A. D. - Ação da cardioplegia na proteção miocárdica: estudo experimental através das réplicas de criofraturas. Rev. Bras. Cir. Cardiovasc. 2(3): 200-211. 1987.

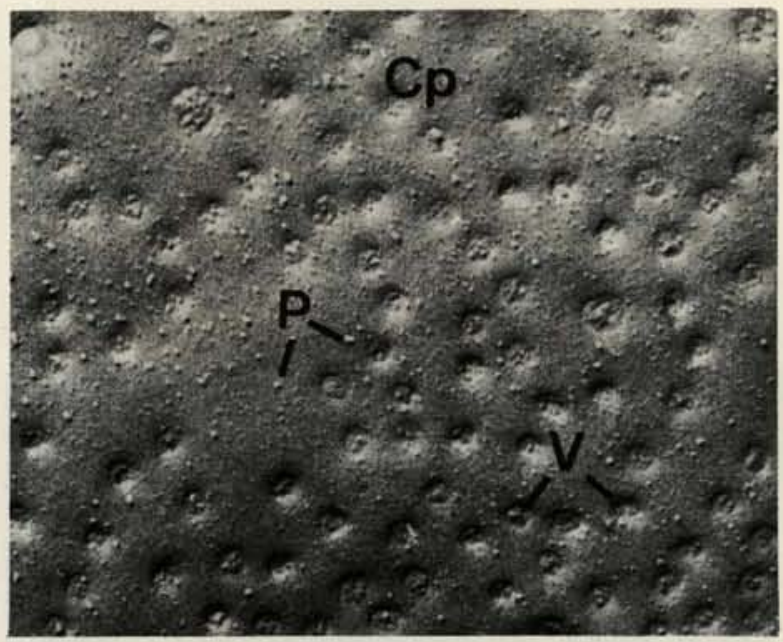

Fig. $10-360$ minutos de reperfusāo miocárdica. Grupo II. Hemiface $P$ do endotélio capilar $(C p)$, com particulas intramembranosas (P) e vesiculas (V) semelhantes ao controle. $(70.000 \mathrm{x})$.

Grupo II) Em relaçāo à amostra 2, obtida no periodo de anóxia, a reperfusāo proporcionou discreta recuperação no número de $\mathrm{PIMs}$ na face $\mathrm{P}$ do sarcolema. Notamos algumas mitocôndrias tumefeitas, porém sem uniformidade. As demais estruturas subcelulares não apresentaram variaçōes detectáveis com o método, especialmente os capilares.

Grupos III e IV) À semelhança da fase de anóxia, nāo observamos alteraçōes ultra-estruturais relevantes decorrentes da reperfusão ( $\mathrm{Sp}, \mathrm{P}$ e $\mathrm{V}$, respectivamente, na Figura 11).

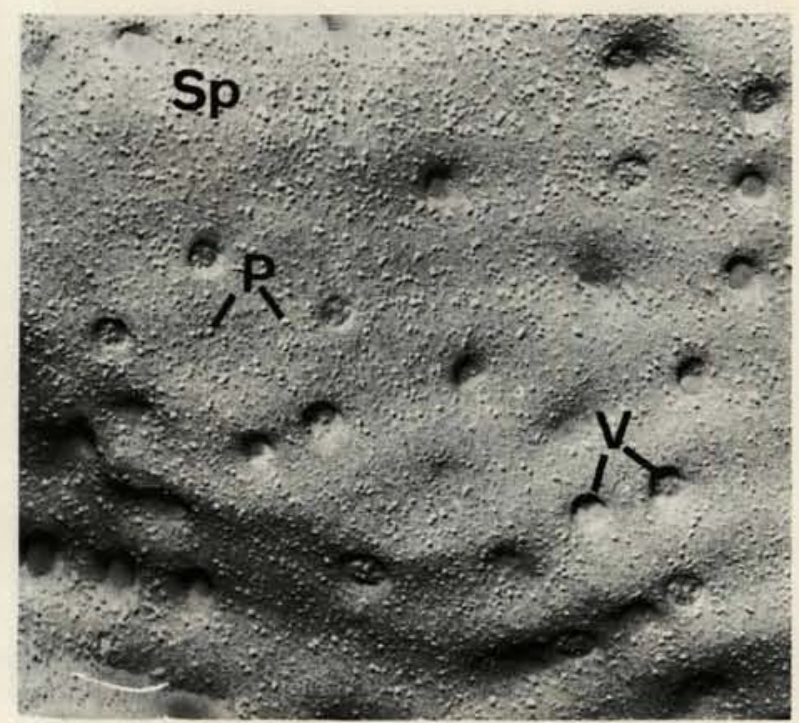

Fig. $11-360$ minutos de reperfusâo miocárdica. Grupo III. Sarcolemá $\mathrm{P}$ apresentando'vesiculas (V) e particulas intramembranosa's (P) com número e distribuição normais. $(70.000 \mathrm{x})$.

\section{COMENTÁRIOS}

Embora descrita há duas décadas, apenas nos últimos anos as réplicas de criofratura vêm sendo empregadas como técnica de alta resolução na análise da arquitetura ultra-estrutural das membranas biológicas, constituíndo-se em método primordial na compreensāo da funçāo celular em nivel molecular ${ }^{26,43}$.

Diversos estudos nos possibilitaram armazenar conhecimentos sobre detalhes da camada bilipidica do sarcolema e eventuais artefatos. Dentre eles, destacamos os de BRANTON ${ }^{6}$, SILVA \& BRANTON ${ }^{49}$, TILLACK \& $M A R C H E S I^{51}$, que, pioneiramente, definiram a existência de planos decorrentes da cisão da membrana celular pela criofratura. Maiores detalhes do envoltório nuclear de plantas e células animais foram adicionados por WUNDERLICH ${ }^{52}$, FRANKE \& KARTENBECK ${ }^{17}$, MAUL et alii ${ }^{36}$, KARTENBECK et alii ${ }^{30}$, BREATHNACH et $a{ } i^{7}$, especialmente decorrentes da observação de mudanças na distribuição de poros nucleares em diferentes condiçōes fisiológicas. Sua aplicação em tecidos musculares esqueléticos e cardíacos, entretanto, foi destacada por CEDERGREN et alii ${ }^{9}$.

Nos animais dos 4 grupos que estudamos, os planos de fratura através da fibra cardiaca resultaram na exposição de extensas hemifaces de membranas, tanto sarcoplasmáticas quanto de endomembranas, visto que a tendência natural da fratura é correr pelas linhas de menor resistência, isto é, entre a bicamada de fosfolípides das membranas. Devido à elevadissima velocidade de congelamento do tecido miocárdico (situada entre $100^{\circ} \mathrm{C} \mathrm{e}-1000^{\circ} \mathrm{C}$ por segundo), a água intre e extracelular passa do estado líqüido ao estado sólido, sem formar rede cristalina, preservando as reais características subcelulares. Assim, com o método da criofratura, foi possivel a análise das partículas intramembranosas (PIMs). SILVA \& BRANTON ${ }^{49}$ interpretaram-nas, inicialmente, como interrupçōes localizadas na continuidade da bicamada hidrofóbica da membrana celular, considerando-as como sítios de conteúdos protéicos intercalados no interior de sua matriz. SESSO \& VAL-SELLA ${ }^{46}$ consideraram-nas como a porção protéica dos complexos glicoprotéicos intercalados na camada bimolecular de lípides, com 5 e 7 micra de altura e largura. Esses relevos, associados ao fato da clivagem celular ocorrer em membranas situadas em diferentes planos, nos possibilitaram obter, através de técnica adequada de sombreamento pela platina, imagens tridimensionais das réplicas de criofraturas nos tecidos.

A distribuição das PIMs nas membranas cardiacas normais não é homogênea. Segundo BREATHNACH et alii $^{7}$, a face dirigida ao interior da célula, tendo atrás de si o espaço extracelular, identificada por BRANTON ${ }^{6}$ por face $E$ ou (-), contém poucas PIMs. Na outra face, que tem atrás de si o meio intracelular (protoplasma), conhecida como face $\mathrm{P}$ ou $(+)$, haveria grande quantidade de PIMs. 
DALLAN, L. A.; OLIVEIRA, S. A.; HIGUCHI, L.; LOPES, E. A.; SESSO, A.; VERGINELLI, G.; JATENE, A. D. - Ação da cardioplegia na proteção miocárdica: estudo experimental através das réplicas de criofraturas. Rev. Bras. Cir. CardiovasC., 2(3): 200-211. 1987.

A variação no número e localização das PIMs tem-se constituído em importante parâmetro, na análise da integridade da célula miocárdica. HIGUCHI et alii ${ }^{24}$, em nosso meio, estudaram as alteraçōes da camada bilipídica do sarcoplasma e endomembranas da fibra cardiaca do cão submetido a autólise, tendo observado queda da densidade numérica das PIMs após 6 horas. Pessoalmente, desenvolvemos trabalho experimental analisando as faces de criofratura e cortes ultrafinos do sarcolema de cardiócitos e plasmalema do endotélio capilar do miocárdio infartado do cão ${ }^{14}$, observando agregação das PIMs a partir de 1 hora e sua diminuição numérica com 3 horas de infarto.

A literatura é escassa em informaçōes sobre a utilização do método de criofratura com o objetivo de detectar lesôes das células cardiacas submetidas a isquemia temporária. Assim, a excelente qualidade técnica das réplicas obtidas pelo Departamento de Patologia Molecular da Faculdade de Medicina da Universidade de São Paulo nos levou a aplicá-la no estudo do grau de proteção celular propiciado pelo emprego de hipotermia e cardioplegia, objeto do presente trabalho.

O exame das réplicas de criofratura dos fragmentos controle do miocárdio dos cães, nos 4 grupos, revelou aspectos condizentes com os da literatura ${ }^{23}$. As características tridimensionais do sarcolema eram normais, com sua configuração ondulada entremeada por pequenas depressões e invaginações tubulares (visibilizadas pela hemiface $\mathrm{P}$ ), correspondentes, respectivamente, às vesículas de endocitose e túbulos T (Figura 1). As PIMs, por sua vez, localizavam-se, preferencialmente, na hemiface $\mathrm{P}$, com distribuição homogênea.

ASHRAF \& HALVERSON ${ }^{2}$ descreveram agregaçāo das PIMs decorridos 45 minutos de isquemia miocárdica. SILVA ${ }^{48}$ atribuiu essas agregações à queda do $\mathrm{pH}$ intracelular decorrente do acúmulo de ácido lático, semeIhante ao que observou com eritrócitos.

Ao final de 60 minutos de anóxia, pudemos observar queda acentuada e agregação das PIM nos cães do grupo normotérmico e, por vezes, descontinuidades na fase lipídica do sarcolema P (Figura 4). Aspectos semeIhantes, porém menos intensos, ocorreram nos cães do grupo II (Figura 7). Nos demais, não foi possivel detectá-los. As descontinuidades na fase lipídica do sarcolema corresponderiam à rotura da membrana celular, caracterizando provável lesão irreversível.

O envolvimento da membrana celular, no processo de lesão da célula em nível molecular, ainda não está bem esclarecido. KIMELBERG ${ }^{31}$ enfatizou as variaçōes no funcionamento normal da célula decorrentes das alterações das proteínas e lípides de suas membranas. Embora ainda sem maior comprovação, existem evidências de que um dos sinais importantes de injúria celular pela isquemia seria a alteração de permeabilidade de suas membranas, através do comprometimento das estruturas protéicas.
Com a recirculação, haveria retenção de fluidos através da maior permeabilidade celular e pela perda de habilidade da célula em auto-regular seu volume. Segundo ASHRAF \& HALVERSON ${ }^{2}$, o edema observado nessas células contribuiria, de forma efetiva, na rarefação das PIMs e nos transtornos da função celular.

Após reperfusāo, a inspecção das superfícies das membranas não demonstrou aspecto uniforme, especialmente no Grupo I. Neste, pudemos observar que, em 3 dos cães, houve piora no aspecto do sarcolema, com diminuição e agregação acentuadas das PIMs, e grandes áreas de descontnuidade de sua fase lipídica. Em 2 outros cães, em contrapartida, houve nítida regressão nas alterações morofológicas até então observadas, assumindo aspecto semelhante ao controle. Estes achados são conflitantes com o observado por ASHRAF \& HALVERSON ${ }^{2}$, que verificaram caráter irreversivel nas lesōes miocárdicas promovidas por isquemia acima de 45 minutos, seguidas de reperfusão. COLEMAN et alii ", estudando células renais de ratos, também não observaram resultados superponíveis aos de Ashraf. Nestas, a agregação das PIMs tornava-se totalmente reversivel após reperfusão, mesmo em períodos isquêmicos superiores a 60 minutos. A diferença entre os resultados encontrados por Ashraf e Coleman decorreu, muito provavelmente, de variações de respostas à isquemia próprias de cada órgão. Neste estudo, diferentemente de Ashraf, nāo foi generalizado o achado de lesão irreversivel. Dois cães do grupo normotérmico mostraram regressão de lesão morfológica com a reperfusão. Isto, possivelmente, está ligado ao fato de que o músculo papilar posterior analisado por Ashraf é sabidamente uma região altamente susceptivel à anoxia ${ }^{29}$.

Devemos lembrar, também, que 2 cães do Grupo I não se mantiveram hemodinamicamente sem $o$ auxílio da circulação extracorpórea, o que pode ter propiciado menor distensão e melhores condiçōes de perfusão ao miocárdio lesado.

Ao analisarmos as mitocôndrias através das réplicas de criofratura, verificamos seu comprometimento apenas nos grupos I e II, especialmente por seu alongamento e tumefação, além da diminuição das PIMs na face $E$ da membrana mitocondrial externa (Figura 6). Com a reperfusão, entretanto, pudemos observar um pequeno número de mitocôndrias com severas alteraçōes estruturais (Figura 9), caracterizadas pelo aspecto liso de sua membrana interna e presença de pequenas fendas em sua membrana externa (face E), ao lado de outras virtualmente normais. Este assincronismo difere do observado no sarcolema, em que, após a reperfusâo, todas as membranas de determinados miocárdios apresentaram, homogeneamente, sinais de recuperação. Acreditamos que as mitocôndrias menos lesadas pela anóxia obtiveram certo grau de reparaçāo, readquirindo sua morfologia peculiar. As mais comprometidas, entretanto, com a reperfusāo podem ter evoluído para total desarranjo estrutural. 
DALLAN, L. A.; OLIVEIRA, S. A.; HIGUCHI, L.; LOPES, E. A.; SESSO, A.; VERGINELLI, G.; JATENE, A. D. - Ação da cardioplegia na proteção miocárdica: estudo experimental através das réplicas de criofraturas. Rev. Bras. Cir. Cardiovasc., 2(3): 200-211. 1987.

COLEMAN et alii " caracterizaram, por estudos de criofratura, as alterações em núcleos isolados de rins de ratos submetidos a isquemia. Constataram que o número de poros nucleares/micra 2 diminuía pela metade, após 20 minutos de supressão sangüinea. Este número apresentava pouco decréscimo até 120 minutos de isquemia, a partir do que a deterioração da estrutura dos poros tornava-se evidente. Não verificamos aspectos semelhantes em nenhum dos grupos, tendo observado boa conservação da membrana nuclear, com provável preservação de sua função. Atribuímos estas variações à maior resistência do núcleo da célula miocárdica, além de estarmos comparando animais e tempos diferentes.

O exame das réplicas de criofratura revelou, decorridos 60 minutos de anóxia, capilares bem preservados ao lado de outros bastante comprometidos nos grupos I e II. As células endoteliais alteradas exibiam diminuição no número de vesículas de endocitose e de PIMs, às vezes com áreas de descontinuidade da fase lipídica.
A recirculação propiciou nítida reparação aos capilares em todos os grupos. O número de PIMs, assim como o número de vesículas de endocitose, aproximaram-se bastante dos encontrados nas amostras de controle (Figura 10).

Baseados nas observaçōes das réplicas de criofratura, pudemos inferir a alta especificidade do método na avaliação dos meios de proteção do miocárdio submetido a isquemia, especialmente por sua sensibilidade no estudo das membranas celulares.

O estudo sugere que não houve diminuição no número de PIMs por unidade de superfície, nem sua agregação, nos grupos que receberam solução cardioplégica associada a hipotermia. O mesmo não ocorreu nos demais, evidenciando a eficácia da solução cardioplégica como método de preservação do miocárdio, embora não tenhamos observado superioridade da solução contendo sangue autógeno sobre a acelular.

RBCCV 44205-41

DALLAN, L. A.; OLIVEIRA, S. A.; HIGUCHI, L.; LOPES, E. A.; SESSO, A.; VERGINELLI, G.; JATENE, A. D. - The cardioplegic action in the myocardial protection: experimental study through freeze fraction replictions. Rev. Bras. Cir. Cardiovasc., 2(3): 200-211, 1987.

ABSTRACT: Evaluation of myocardial protection by cardioplegic solutions and hipothermia in anoxic hearts. An experimental study. This investigation was performed in a group of 20 dogs submitted to myocardial anoxia by cross-clamping of the ascending aorta for sixty minutes under extracorporeal circulation, followed by reperfusion for 360 minutes. Ultrastructural changes of the myocardium were studied. The animals were divided into 4 groups of 5 dogs each. In the first group (control), myocardial anoxia was induced in normothermia and no cardioplegic solution was administered. In the second group, the body temperature was reduced to $28^{\circ} \mathrm{C}$ before the onset of myocardial anoxia, and no cardioplegic solution was used. In the third and fourth groups, in addition to $28^{\circ} \mathrm{C}$ systemic hypothermia, coronary infusion of $4^{\circ} \mathrm{C}$ cardioplegic solutions were performed immediately and after 30 minutes of clamping of the aorta. The cardioplegic solutions utilized have $\mathrm{NaCl}, \mathrm{KCl}, \mathrm{CaCl}_{2}$, Lidocaine, Verapamil, $\mathrm{NaHCO}_{3}, \mathrm{MgSO}_{4}$ and the infusion vehicle was $5 \%$ glucose solution in Group III, and blood in Group IV. Biopsies for freeze-fracture replication were obtained from the anterior wall of the left ventricle, before and after 60 minutes of myocardial anoxia, and 360 minutes after reperfusion. The alterations in sarcolemma and celular organeles due to anoxia or myocardial reperfusion was observed, specially through the diminution and aggregation of intramembranous particles in its $\mathrm{P}$ surface. We may conclude that both cardioplegic solutions used, associated to hipothermia, protect efficiently the myocardial cells against anoxia. It was not possible, however, to demonstrate any superiority of the blood solution over an acellular solution. Systemic hypothermia as a single method was not sufficient to offer good protection to the anoxic myocardium. The animals of Group I (control) showed severe compromise of the structure and function of the myocardium.

DESCRIPTORS: myocardial protection, cardioplegia; myocardial protection, experimental.

Símbolos e àbreviaturas utilizados nas micrografias eletrônicas das réplicas de criofratura e legendas:

$\begin{array}{cl}\mathrm{p} & - \text { Hemiface } P \\ \mathrm{e} & - \text { Hemiface } E \\ \mathrm{Cp} & - \text { Face } \mathrm{P} \text { da célula endotelial do capilar } \\ \mathrm{Ce} & - \text { Face } E \text { da célula endotelial do capilar } \\ \mathrm{F} & - \text { Miofilamentos } \\ \mathrm{MEp} & - \text { Face } P \text { da membrana mitocondrial externa }\end{array}$


DALLAN, L. A.: OLIVEIRA. S. A.: HIGUCHI, L.: LOPES. E. A.: SESSO, A.: VERGINELLI. G.: JATENE. A. D. - Açào da cardioplegia na proteção miocárdica: estudo experimental atraves das replicas de criofraturas. Rev. Bras. Cir. CardiovasC. 2(3): 200-211. 1987.

\begin{tabular}{|c|c|c|}
\hline Mlp & - & Face $P$ da membrana mitocondrial interna \\
\hline MEe & - & Face $E$ da membrana mitocondrial externa \\
\hline Mle & - & Face $E$ da membrana mitocondrial interna \\
\hline $\mathrm{NEe}$ & - & Face $\mathrm{E}$ da membrana nuclear externa \\
\hline NIp & - & Face $P$ da membrana nuclear interna \\
\hline $\mathrm{O}$ & - & Áreas de desaparecimento de miofilamentos \\
\hline $\mathrm{P}$ & - & Partícula intramembranosa \\
\hline po & - & Poro da membrana nuclear \\
\hline $\mathrm{Sp}$ & - & Face $\mathrm{P}$ do sarcolema \\
\hline $\mathrm{Se}$ & - & Face $E$ do sarcolema \\
\hline $\mathrm{Tp}$ & - & Face $P$ do túbulo $T$ \\
\hline $\mathrm{Te}$ & - & Face $E$ do túbulo $T$ \\
\hline Vp & - & Face $P$ da vesícula de endocitose \\
\hline $\mathrm{Ve}$ & - & Face $E$ da vesícula de endocitose \\
\hline & - & Particulas intramembranosas agregadas \\
\hline & - & Fissuras na face $E$ da membrana mitocondrial externa \\
\hline & - & Descontinuidade da fase lipídica do sarcolema \\
\hline & - & Dilatação saculares das cristas mitocondriais \\
\hline
\end{tabular}

Obs: Fragmentos obtidos da face anterior do VE

\section{REFERÊNCIAS BIBLIOGRÁFICAS}

1 AHMED, S. A.; WILLIAMSON, J. R.; ROBERTS, J. R.; ROBERTS, R.; CLARK, R. E.; SOBEL, B. E. - The association of increased plasma MB CPK activity and irreversible ischemic myocardial injury in the dog. Circulation, 54(2):187-193, 1976.

2 ASHRAF, M. \& HALVERSON, C. A. - Structural changes in the freeze-fracture sarcolema of ischemic myocardium. Am. J. Pathol., 88(3):583-594,1977.

3 BELLOTTI, G. M. V. - Contribuição ao estudo das alteraçōes ultramicroscópicas e metabólicas do coração em parada anóxica, durante o emprego de circulação extracorpórea. São Paulo, 1970. (Tese Doutoramento Faculdade de Medicina da USP).

4 BIGELOW, W. G.; CALLAGHAM, J. C.; HOPPS, J. A. General hypothermia for experimental intracardiac surgery. Ann. Surg., 132(3):531-538, 1950.

5 BRAILE, D. M.; BILAQUI, A.; ANACLETO, J. C.; ARAÚJO. J. D.; BELLINI, A. J.; GARZON, S. A.; GRECO, O. T.; ARDITO, R. V.; AYOB, J. C.; BAUCIA, J. A.; WICHTENDAHL, R.F.; KURODA, G. Y.; LORGA, A. M. Proteção miocárdica por cardioplegia. Arq. Bras. Car. diol., 33(Supl. 1):199-210, 1979.

6 BRANTON, D. - Fracture faces of frozen membranes. Proc. Nat. Acad. Sci. (Washington)55:1048-1056, 1966.

7 BREATHNACH, A. S.; GOODMAN, T.; STOLINSKI, G.; GROSS, M. - Freeze fracture replication of cells of stratum of human epidermis. J. Anat. (London)114(1):65-81, 1973.
8 BRETSCHNEIDER, H. J.; HÜBNER, G.; KNOLL, D.; LOHR, B.; NORDBECK, H.; SPIECKERMANN, P. G. - Myocardial resistence and tolerance to ischemia; physiological and biochemical basis. J. Cardiovasc. Surg. (Torino) 16(3): 241-260, 1975.

9 CEDERGREN, E.; THORNELL, L. E.; SJÖSTRÖM, M. The mitochondrial envelope as studied by freeze-fracturing. J. Uitrastruct. Res., 44:434-435, 1975.

10 COLEMAN, S. E.; DUGGAN, J.; HACKETT, R. L. - Freezefracture study of changes innuclei isolated from ischemic rat Kidney. Tissue Cell, 6(3):521-534, 1974.

11 COLEMAN, S. E.; DUGGAN, J.; HACKETT, R. L. - Quantitation of particles in the freeze-fractured nuclear membrane after renal ischemia. Virch. Arch. B. Cell. Pathol., 28:101-117.

12 COOLEY, D. A.; BOODWELL, R. D.; BEALL, A. C.; GILL, S. S.; HALLMAN, G. L. - Total cardiac valve replacemente using SCDK-Cutter prosthesis: experience with 250 consecutive patientes. Ann. Surg., 164(3):428-444, 1966 .

13 COOLEY, D. A.; REUL, G. J.; WUKASCH, D. C. - Ischemic contracture of the heart: "stone heart". Am. J. Cardiol.,29:575-580, 1972.

14 DALLAN, L. A.; HIGUCHI, M. L.; LOPES, E.; BELLOTTI. G.; ARMELIN, E.; PILEGGI, F.; VERGINELLI, G.; JATENE, A. D.; SESSO, A. - Análise das faces de criofratura e cortes ultrafinos do sarcolema de cardiócitos e plasmalema do endotélio capilar do miocárdio infartado do cão. Arq. Bras. Cardiol., 43(Supl, 1):33, 1984. (Resumo). 
DALLAN. L. A.; OLIVEIRA, S. A.; HIGUCHI, L.; LOPES. E. A.; SESSO, A.: VERGINELLI. G.: JATENE. A. D. - Açâo da cardioplegia na proteção miocárdica: estudo experimental atraves das réplicas de criofraturas. Rev. Bras. Cir. Cardiovasc. 2(3): 200-211. 1987.

EFFLER, D. B.; KNIGHT Jr., H.F.; GROVES, L. K.; KOLFF, W. J. - Elective cardiac arrest for open-heart surgery. Surg. Gynecol. Obstet., 105(4):407-416, 1957.

16 FOLLETTE, D. M.: MULDER, D. G.; MALONEY Jr., J. V.: BUCKBERG, G. D. - Advantages of blood cardioplegia over continous coronary perfusion or intermittent ischemia: experimental and clinical study. J. Thorac. Cardiovasc. Surg., 76(5);604-619, 1978.

17 FRANE, W. \& KARTENBECK, J. - Structure of nuclear membranes isolated from braim cells. Experientia (Basel) 25:396-398, 1969 .

18 GAY Jr., W. A. \& EBERT, P. A. - Functional, metabolic and morphologic effects of patassium-induced cardioplegia. Surgery, 74(2):284-290, 1973.

19 GIBBON Jr., J. H.; MILLER, B. J.; FINEBERG, C. - An improved mechanical and lung apparatus. Med. Clin. N. Am., 37:1603-1624, 1953

GOMES, O M.; MORAES, N. L. B.; FIORELLI, A. I.; BRUM, J. M.; RIBEIRO, M. P.; CALONGE, H. C.; ARMELIN, E.; BITTENCOURT, D.; ZERBINI, E. J. — Parada cardiaca anóxica. Três horas de proteção: nova solução cardioplégica. Arq. Bras. Cardiol., 36(1):8-12, 1981.

21 GOMES, O. M.; PEDROSO, F. I.; PEREIRA, S. N.; AYOUB, A. H.; KWANG, W. T.; BITTENCOURT, D.; ZERBINI, E. J. - Mitochondrial anzymatic alterations produced in the myocardium by anoxic cardiac arrest. J. Thorac. Cardiovasc. Surg., 67(4):649-658, 1974.

HEARSE, D. J.; STEWART, D. A.; BRAIMBRIDGE, M. V. - Cellular protection during myocardial ischemia: the development and characterization of a procedure for the induction of reversible ischemic arrest. Circulation, 54(2):193-202, 1976

23 HIGUCHI, M. L. - Observações em cortes ultrafinos e réplicas de criofratura de territórios miocárdicos de cão submetidos a 1, 3, 6 e 24 horas de isquemia. São Paulo, 1985. (Tese doutoramento - Faculdade de Medicina da USP).

24 HIGUCHI, M. L.; DALLAN, L. A.; SILVESTRE, L. L.; LOPES, E. A.; BELLOTTI, G.; ARMELIN, E.; PILEGGI, F.; SESSO, A. - Modificaçōes exibidas pelo sarcolema e endomembranas da fibra cardiaca de cão em tempos sucessivos de autólise através da análise das faces de criofratura e de cortes ultrafinos. Arq. Bras. Cardiol., 43(Supl 1): 38,1984 . (Resumo).

HÖELSCHER, B. - Studies by electron microscopy on the effects of magnesium chloride-procaineamide or potassium citrate on the myocardium in induced cardiac arrest. J. Cardiovas. Surg. (Torino) 8(1):163-166, 1967.

HUDSON, C. S.: RACH, J. E.: GRAHAM, W. F. - Introduction to sample preparation for freeze-fracture. In: RASH, J. E. \& HUDSON, C. S. eds Freeze-fracture. methods, artefacts and interpretations. New York, Raven Press, 1979. p. 1-10.

27 HUFNAGEL, C. A. \& CONRAD, P. W. - The direct approach for the correction of aortic insufficiency. JAMA. 178(3):275-279, 1961

28

JANTENE, A. D. - Hipotermia seletiva do miocárdio. Rev. Assoc. Med. Bras., 9(4):114-116, 1963.

29 JENNINGS, R. B.; BAUM, J. H.; HERDSON, P. B. - Fine structural changes in myocardial ischemic injury. Arch. Pathol., 79(1):135-143, 1965

30 KARTENBECK, J.: ZENTGRAF, H.; SCHEER, U.: FRANKE, W. W. - The nuclear envelope in freeze-etching. $A d v$. Anat. Embryol. Cell. Biol., 45:7-53, 1971

31 KIMELBERG, H. K. - Protein-liposome interactions and their relevance to the structure and function of cell membranes. Moll. Cell. Biochem., 10(3):171-190, 1976.

32

KIRSCH, U.; RODEWALD, G.; KALMAR, P. - Induced ischemia arrest. J. Thorac. Cardiovasc. Surg.. 63(1):121-130, 1972.

33 LEWIS, F. J. \& TAUFIC, M. - Closure of atrial septal defects with the aid of hypothermia: experimental accomplishment and the report of one successful case. Surgery, 33(1):52-59, 1953.

34 LILLEHEI, C. W.; De WALL, R. A.; GOTT, V. L.; VARCO. R. L. - The direct vision correction of calcific aortic stenosis by means of a pump-oxigenator and retrograde coronary sinus perfusion. Dis. Chest. 39(2):123-132, 1956

35 LOPES, E. A. - Aspectos microscópicos e submicroscópicos do infarto do miocárdio experimental do cão submetido a revascularização precoce. São Paulo, 1973. (Tese Doutoramento - Faculdade de Medicina da USP).

36 MAUL, G.G.; PRICE, J. W.; LEIBERMANAM. W. - Formation and distribution of nuclear pore complexes in interphase. J. Cell. Biol., 51: 405-418, 1971.

37 MAZZA, L. V.: ANVERSA, P.:MORGUTTI, L.; TOSO, A. - Changes of the myocardial ultrastructure during open heart surgery with extracorporeal circulation. $J$. Cardiovasc. Surg. (Torino) 17(2): 212-228, 1969.

38 MELROSE, D. G.: DREYER, B.; BENTALL, H. H.; BAKER, J.B. - Elective cardiac arrest. Lancet, 2:21-22, 1955

39 MURAD, H.; QUEIROZ, A. D.; MATTOS, S. C.; PIEDADE, M. M.: ALBUQUERQUE, P. C.; MURAD, L. H.: PEREIRA, G. C.; BASTOS, E. S.; JAZBIK, A. P. - Proteção miocárdica por caridoplegia sangüinea durante circulação extracorpórea: avaliaçāo ultra-estrutural miocárdica no cão. Arq. Bras. Cardiol., 41(2):231-239, 1983.

40 NELSON, R. L.; FEY, K. H.; FOLLETTE, D. M.; LIVESAY, J. J.; De LANG, E. C.; MALONEY Jr., J. V.; BUCKBERG, G. D. - Intermittent infusion of cardioplegic solution during aortic cross-clamping. Surg. Forum, 27:241-243, 1977 
DALLAN, L. A.; OLIVEIRA, S. A.; HIGUCHI, L.; LOPES, E. A.; SESSO, A.; VERGINELLI, G.; JATENE, A. D. - Ação da cardioplegia na proteção miocárdica: estudo experimental através das réplicas de criofraturas. Rev. Bras. Cir. Cardiovasc. 2(3): 200-211. 1987.

41 OPIE, L. H. - Metabolism of the heart in health and disease. Part III. Am. Heart J., 77(3):383-410, 1969.

42 RAJU, S.; GIBSON, W. J.; HEATH, B.; LOCKHART, V.; CONN, H. - Experimental evaluation of coronary infusates in dogs. Arch. Surg., 110:1374-1382, 1975.

43 RACH, J. E. \& HUDSON, C. S. - Preface. In: RACH, J. E. \& HUDSON, C. S. eds. Freeze-fracture: methods, artefacts and interpretations. New York, Raven Press, $1979 \mathrm{p}$.

44 REIDEMEISTER, J. C.; GEHL, H.; SPIECKERMAN, P. G.; ORELLANO, L. E. - Untersuchung der Kardioplegie durch extracellularem Natrium und Calciumentzung und Novocaingabe im überlevensversuch am hund. Langebecks Arch. Klin. Chir., 313:1043-1049, 1965.

45 ROE, B. B.; HUTCHINSON, J. C.; FISHMAN, N. H.; ULLYOT, D. J.; SMITH, D. L. - Myocardial protection with cold, ischemic potassium induced cardioplegia. J. Thorac. Cardiovasc. Surg., 73(3):366-374, 1977.

SESSO, A. \& VAL-SELLA, M. V. - Estudos em cortes ultrafinos e em réplicas de criofratura do processo de exocitose em células hipofisárias do bagre e em células endócrinas do pâncreas do rato. Bol. Fisiol. Animal (USP) 4:101-121, 1983.
47 SHUMWAY, N. E.; LOWER, R. R.; STOFER, R. C. Selective hypothermia of the heart in anoxic cardiac arrest. Surg. Gynecol. Obstet., 109:750-754, 1959.

48 SILVA, P. P. - Translational mobility of the membrane intercalated particles of human erythrocyte ghosts: $\mathrm{pH}$ dependent, reversible aggregation. J. Cel. Biol. 53:777-787, 1972.

49 SILVA, P. P. \& BRANTON, D. - Membrane splitting in freeze-etching: covalently bound ferritin as a membrane maker. J. Cell. Biol., 45:598-605, 1970

50 TAKAMOTO, S.; LEVINE, F. H.; LARAIA, P. J.; ADZICK. N. S.; FALLON, J. T.; AUSTEN. W. G.; BUCKLEY, M. J. - Comparison of single-dose and multipl-dose crystalloid and blood potassium cardioplegia during prolonged hypothermic aortc occlusion. J. Thorac. Cardiovasc. Surg., 79(1):19-28, 1980.

51 TILLACK, T. W. \& MARCHESI, V. T. - Demonstration of the outer surface of freeze-etched red blood cell membranes. J. Cell. Biol., 45:649-653, 1970.

52 WUNDERLICH, F. - The macronuclear envelope of tetrahymena pyriformis $\mathrm{GL}$ in different physiological states. I: quantitative structural data. Exp. Cell. Res. 56:369-374, 1969. 